Volume 2

Number 1 July

$7-31-2018$

\title{
Living with earthquake hazards in South and South East Asia
}

Afroz Ahmad Shah

University of Brunei Darussalam, afroz.shah@ubd.edu.bn

Talha Qadri

Universiti of Brunei Darussalam

See next page for additional authors

Follow this and additional works at: https://scholarhub.ui.ac.id/ajce

Part of the Social and Behavioral Sciences Commons

\section{Recommended Citation}

Shah, Afroz Ahmad; Qadri, Talha; and Khwaja, Sheeba (2018). Living with earthquake hazards in South and South East Asia. ASEAN Journal of Community Engagement, 2(1).

Available at: https://doi.org/10.7454/ajce.v2i1.105

Creative Commons License

(c) (i) (2)

This work is licensed under a Creative Commons Attribution-Share Alike 4.0 License.

This Research Article is brought to you for free and open access by the Universitas Indonesia at ASEAN Journal of Community Engagement. It has been accepted for inclusion in ASEAN Journal of Community Engagement. 


\title{
Living with earthquake hazards in South and Southeast Asia
}

\author{
Afroz Ahmad Shaha ${ }^{*}$, Talha Qadria, Sheeba Khwajab \\ ${ }^{a}$ University of Brunei Darussalam, Brunei Darussalam \\ bFaculty of Social Sciences, Department of History, University of Brunei Darussalam, Brunei Darussalam
}

Received: March 7th 2018|| Revised: May 24th $\&$ June 22 ${ }^{\text {nd }}, 2018||$ Accepted: July $9^{\text {th }}, 2018$

\begin{abstract}
A large number of geological studies have shown that most of the Asian regions are prone to earthquake risks, and this is particularly significant in SE Asia. The tectonics of this region allow the geological investigators to argue for severe vulnerability to major and devastating earthquakes in the near future. This remind us of the devastations of Nepal in 2015, of Japan in 2011, of the significant destruction of life and property at Acehnese and Thai coasts in 2004, and of Kashmir and New Orleans in 2005. Such example of destructions could be minimized to a greater extent if proper scientific and administrative framework are established. This was surely lacking in most of the above examples. And previous studies have suggested that scientists and administrative authorities should work together to map the actual vulnerabilities on ground, and simultaneously educate people about the probable causes of earthquakes and how to minimize the destruction. Here we further show that nations with a turbulence political past and an ongoing unstable political problem are more likely to score less on securing its people from disasters. And this score can significantly deteriorate if a nation does not work on eradication of corruption as it can make monsters out of ordinary disasters. We further show that South and Southeast Asian region are relatively young nations that are still in post-colonial period and are largely involved in strengthening of their economies as well as cleaning of the post-colonial problems. While the increasing values of gross domestic product (GPD) per capita and a decent rise in literacy rates are good news to win battle with disasters, these nations have to work really hard to eradicate corruption and spend more on scientific research and awareness about earthquake disasters.
\end{abstract}

Keywords: Earthquake hazards; Southeast Asia: Literacy rate; Corruption; Education

\section{Introduction}

The San Andreas Fault, a major dextral strike-slip fault system (e.g. Forand et al., 2018) in US, is probably one of the most well-known structures to mankind. If you talk to random people anywhere on the globe and ask them about faults, there are more chances of getting them right on this fault if not on other major fault systems of the world. We did exactly this, asking people in Brunei, Miri and Sabah (Malaysia) about earthquakes and faults, and the answers did not surprise us. While most of them are not aware about faults, as expected, however, many knew about San Andreas Fault, possibly because the movie San Andreas that was released in 2015, and is based on the San Andreas Fault system. When we informed our Geology undergraduate students about the existence of major fault system in Asia, their facial expressions surprised us because they were not aware of such fault systems in the neighborhood and were puzzled to discover that a number of large scale dextral strike-slip fault systems also exist in Asia, particularly in South and South East Asian regions (e.g. Sumatran Fault System, Sanging fault system, and Karakurum fault system). In contrast, all of them knew about the existence of San Andreas Fault! This is interesting, because typically a Geology graduate student should be aware of the various fault systems in the neighborhood. What makes such a stark distinction that even our Geology students are not familiar with the major fault system in Asia? One of the reasons is the lack of awareness and

*Correspondence Author: afroz.shah@ubd.edu.bn 
updated scientific information, particularly to students, who are expected to know about the latest research on faults because they are the future scientists and community builders and will help us to win the ongoing battle with earthquake disasters.

Therefore, the first motivation of our contribution is to highlight the occurrence of some of the major fault systems in South and SE Asia, and to understand what has been achieved so far in understanding of the geology of these faults plus the status of our preparedness to tackle any future earthquake hazard associated with these faults.
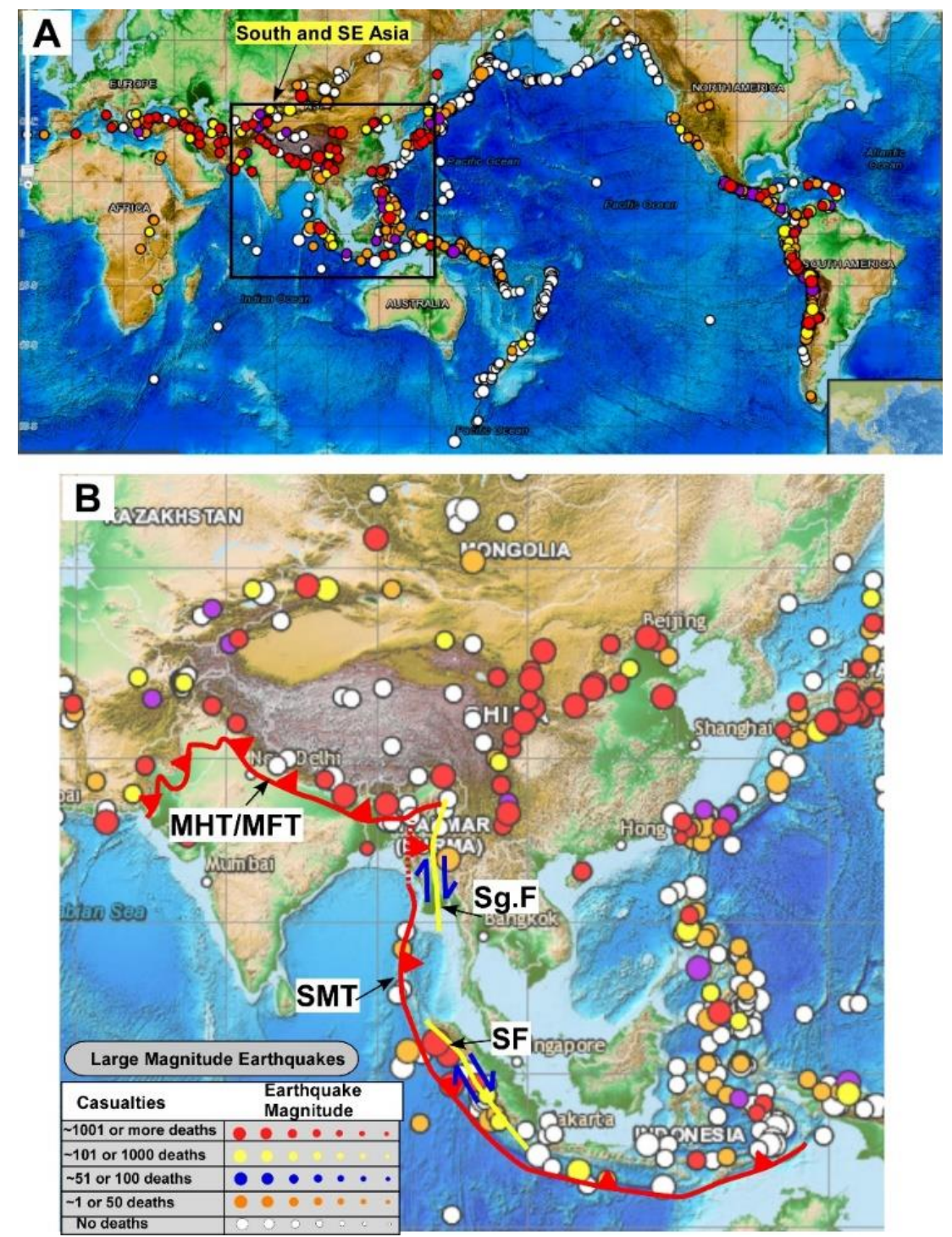

Fig. 1 (a) Shows global distribution of significant earthquake, and the associated casualties. Color of the circle indicates number of deaths (e.g. red indicates high number of deaths), and the size of the circle indicates the earthquake magnitude. (b) Shows the same figure as above plus the major earthquake sources (see text for details). MHT $/$ MFT = Main frontal thrust, SMT= Sunda megathrust fault, SF= Sumatran fault, Sg.F= Sagaing fault.

Source: These figures are prepared from the data obtained on $3^{\text {rd }}$ March 2018 from Natural Hazards Viewer of NOAA (2018) 
Our second motivation is to understand why poor and developing nations are often more prone to disasters (e.g. Ambraseys and Bilham, 2011) and what can be done to avert this. This becomes obvious when we learn that earth scientists have spent $\sim 100$ years to map and understand the science of earthquakes, and have successfully progressed in forecasting earthquakes, which has unequivocally emerged as a useful tool in dealing with such hazards (Philibosian, et al., 2017). However, the prediction of earthquakes has remained a major challenge and this may continue in the future (Hough, 2010; Shah, 2014). It is true that our knowledge about the causes and associated hazards related to the future destructive earthquakes has greatly evolved because of the new mapping techniques and the availability of better resolution of data, which has helped us to understand faults at micro and mega scales (e.g. Hough, 2010). However, with all this knowledge we are still unable to save life, and this is not just because of the complex nature of science of faulting, but also largely due to poor quality of updated scientific education, lack of awareness (Ambraseys and Bilham, 2011), political stability versus instability, economic index of a country (see below), and corruption (Ambraseys and Bilham, 2011). Therefore, through this contribution we also look at these aspects and offer solutions to deal with earthquake hazards in South and SE Asia where a large portion of the population remains at greater risks to earthquake related hazards.

The connection between the devastating nature of a disaster and the level of preparedness to handle such a disaster on ground is well established (Ambraseys and Bilham 2011; Cummins, 2017). This becomes obvious when we compare, for example, the extent of devastation caused by the same magnitude earthquakes at two different geographical locations of the world; one well prepared, and other not at all (Figs. 2 and 3). More importantly, the correlation between preparedness of a nation to handle disasters and the extent of corruption, and poverty is now well established (e.g. Ambraseys and Bilham 2011; Hough, 2010). It is therefore not just about how good we understand science of disasters, but also how that information has percolated into a nation, and what actions have been taken or are under considerations (Hough, 2010). Look at the extent of devastation caused by Mw 7.0 earthquake that occurred on $12^{\text {th }}$ January in Haiti (DesRoches et al., 2011; Figs. 3) and compare it with a similar event in New Zealand on $3^{\text {rd }}$ September 2010 (Figs. 3), a stark difference emerges not only in the total number of fatalities, which are around 300,000 or 85000 (Ambraseys and Bilham 2011) in Haiti, and none in New Zealand, but also in the extent and scale of destruction. The earthquake totally devastated Haiti, one of the poorest countries in the world (DesRoches et al., 2011), ranked 145 out of 169 on the UN Human Development Index (UNDP 2010).

This clearly suggests that poverty is one of the worst things to happen to a nation because it can make monster out of even ordinary hazards. What is more, poor nations often face high corruption rates, which significantly hinders their preparedness for a risk that often turns into a major disaster (Ambraseys and Bilham 2011). This is true to Haiti as most people in Haiti have no access to basic needs. For example, only $10 \%$ or less have access to potable tap water, and just one-third have access to electricity (UNSD 2010). Moreover, about half of Haiti's population lives on less than 1 US dollar per day, and this nation also has one of the highest rates of mortality among infants, children under 5 , and during maternity among any country in the Western Hemisphere (UNSD 2010). Expecting such a nation to prepare for a potential disaster is, in basic terms, imprudent and unfeasible. We have continuously witnessed throughout the human history that nations become victims to various disasters 
because of political instability, poverty, corruption, and lack of resources (see below for details).

Further, the preparedness of a country hugely depends on the stable political landscape of that nation. A quick comparison suggests that New Zealand (a stable nation) was much more prepared than Haiti (e.g. Crowley and Elliott, 2012). However, technically New Zealand failed to save people when on 21 February 2011 a medium magnitude earthquake devastated Christchurch and caused 181 deaths. This is rather surprising because both events occurred in New Zealand, a nation that has developed in the womb of earthquakes, a relatively wellequipped nation to cope with earthquake disasters. So, the conclusion that New Zealand is well equipped to face medium to large magnitude earthquake may not be true. Then, what might have contributed to the extent of damage associated with a relatively smaller earthquake event in 2011 versus no damage during a rather bigger event in 2010? The answer perhaps seems to lie in hypocenter depth, type of movement on the fault, and the distance to nearby population (Fig. 3) plus the fact that previous event had partially damaged structures, and therefore such buildings were easy to topple during a subsequent medium magnitude earthquake. Moreover, the extensive occurrence of liquefaction, similar to what happened during 2005 Kashmir earthquake (Malik et al., 2007), greatly aggravated the problem and caused serious damage; a hazard turned into a major disaster (e.g. Crowley and Elliott, 2012).

\section{Methods}

We have used published and freely available seismological and satellite data to compile the major sources of earthquakes in Asia, and particularly for SE Asia (see below). This data is supplemented with available data on significant earthquakes that have occurred in the region (Figs. 1 and 2). We use the newly compiled regional probabilistic seismic hazard map of SE Asia (Chan et al., 2017) that shows the pockets of high seismic risk near those faults that have recorded high slip rates. However, low slipping faults can also cause significant damage, and this we have witnessed during the recent earthquake that struck Sabah (Malaysia) on $5^{\text {th }}$ June and resulted in loss of 18 people (Shah et al, 2018; Wang et al, 2017). We also compare the devastation of similar magnitude earthquakes occurring in nations that are relatively well prepared with those that are unprepared. Furthermore, the correlation of earthquake destructions with poverty of a nation is suggested, and the previous works have established that often poor nations are also facing corruption problems, which further aggravates the earthquake destructions (Ambraseys and Bilham, 2011). Here we subsequently compare the post-colonial periods in South and Southeast Asian countries and try to understand how much progress these nations have made after independence. Additionally, the impact of colonial period on the progress of seismic resilience of these nations is also tested. We also compare literary map with the seismic resilience of the countries to find a link. The Gross Domestic Product per capita and corruption perception index maps are used to map and predict the future course of South and Southeast nations. Finally, we overlay the newly developed regional probabilistic seismic hazard map of SE Asia (Chan et al., 2017) on the freely available population density map of the world (Robert Simmon, 2018) to understand the risk, and what needs to be done minimize the possible destruction by a future earthquake. 


\section{Result and Discussion}

Below we highlight some of the major earthquake sources in South and Southeast Asia (Fig. 1A). The Sunda megathrust (SMT), the Sumatran fault zone (SFZ), the Sagaing fault (SF), and the Main Himalayan/frontal thrust (MHT/MFT) are some of the major faults that continuously pose earthquake hazard and risk in the region (Fig. 1). Therefore, here we briefly review the current scientific wisdom in understanding of the genesis of the fault systems, progress, and preparedness to handle any future medium to large magnitude earthquake. We also discuss the various factors that can influence our progress to achieve the goal of becoming an earthquake resilient community.
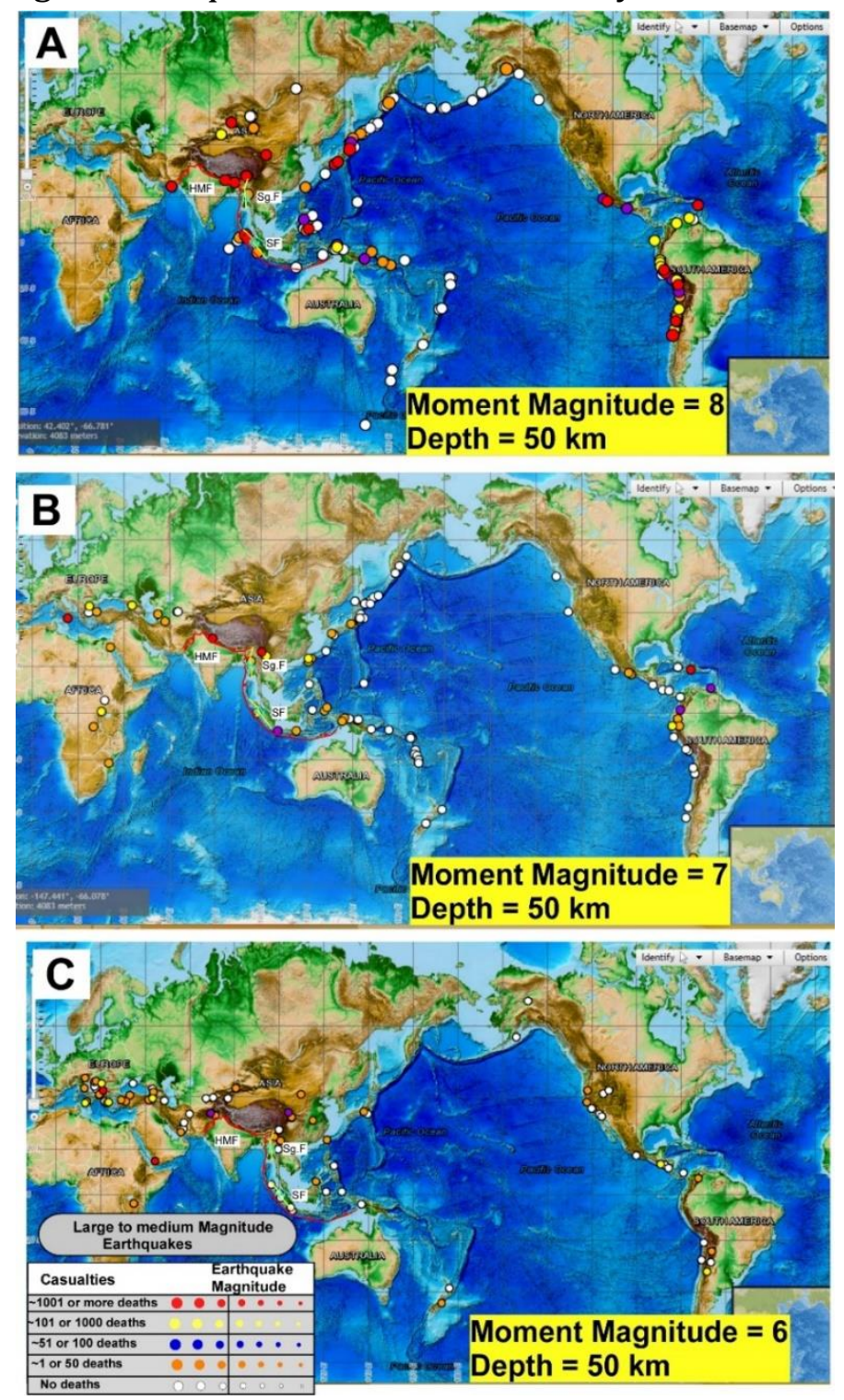

Fig. 2 (a) Shows global distribution of Moment magnitude (Mw) 8 earthquakes and associated casualties. Color of the circle indicates number of deaths (e.g. red indicates high number of deaths), and the size of the circle indicates the earthquake magnitude.

Fig. b shows global distribution of Mw 7, events while as Fig. c shows Mw 6 earthquakes (see text for details)

Source: These figures are prepared from the data obtained on 3rd March 2018 from Natural Hazards Viewer of NOAA (2018) 

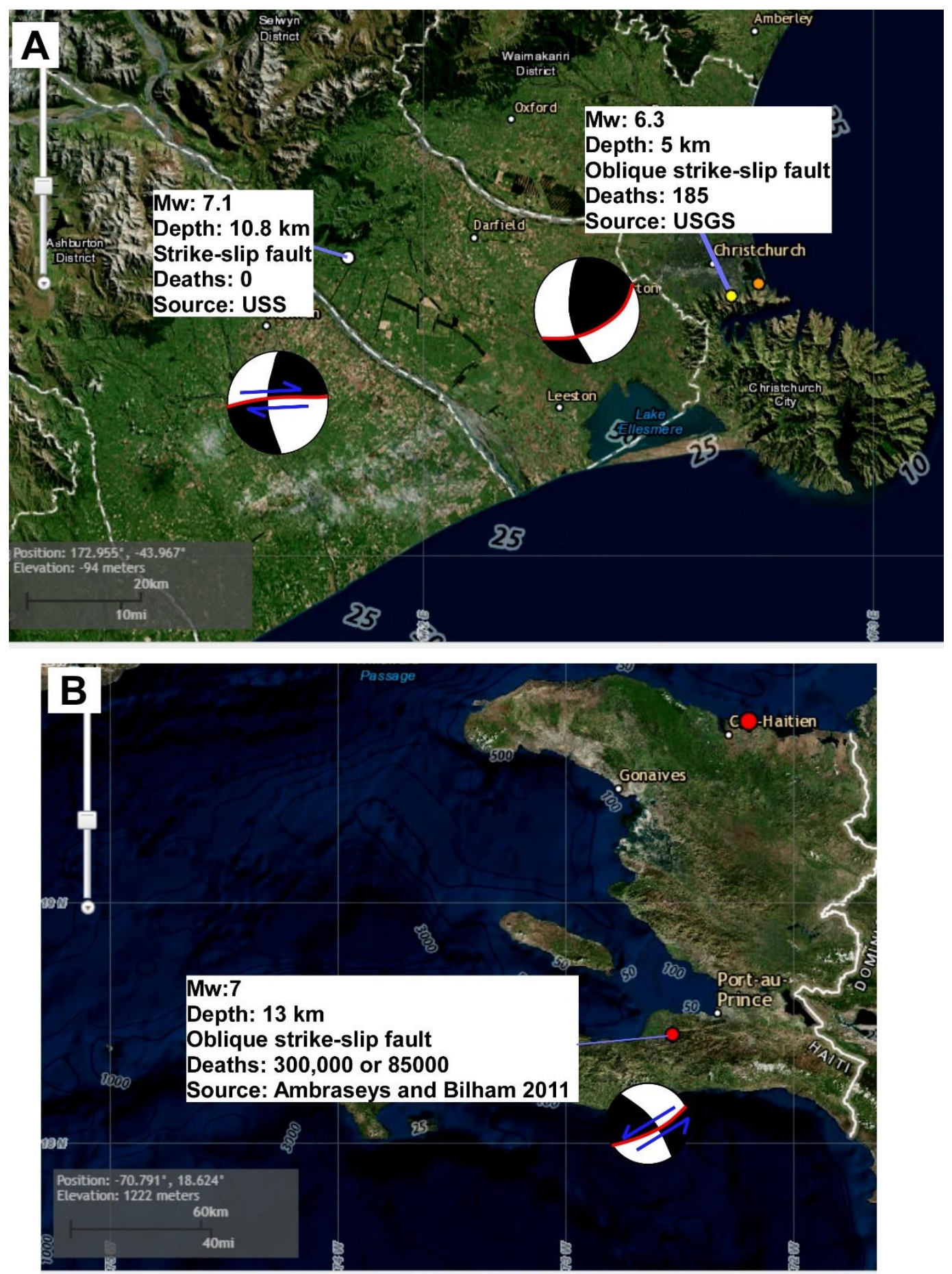

Fig. 3 (a) Shows the Mw 6.3 and Mw 7.1 earthquakes that occurred in New Zealand. The fault plane solutions show the type of fault associated with the earthquakes, and it suggests that an oblique fault (strike-slip with reverse component) caused 6.3 earthquake, while as the dextral strike-slip caused the Mw 7.1 earthquake (b) Shows Mw 7 earthquake that devastated Haiti in 2010 (see text for details).

Source: These figures are prepared from the data obtained on $3^{\text {rd }}$ March 2018 from Natural Hazards Viewer of NOAA (2018), and USGS 


\subsection{Earthquake hazard on the Sunda megathrust fault}

The Sumatra subduction zone marks the present-day active convergent plate boundary where Indo-Australia plate is currently subducting beneath the Sunda plate at an average convergence rate of 5-7 cm/year (Shearer and Bürgmann, 2010; Genrich et al., 2000). This convergence is oblique, and responsible for trench parallel component of fault movement via strike-slip fault system (Sieh, 2007; Sieh and Natawidjaja, 2000). The place where two plates converge at subducting zones is called a megathrust zone and it is where the most of the deadly earthquakes occur (Shah, 2013a). When one solid rock unit resists diving down beneath another solid rock body, the resistance via friction becomes the cause of earthquakes. And this is what happened before the large magnitude earthquake occurring on 26 December 2004 which broke a significant portion of the Sunda megathrust fault. It caused one of the most devastating earthquakes and tsunami in the contemporary times. It is estimated that $\sim 156,000$ to 178,000 people died across more than 11 nations, and $\sim 26,500$ to 142,000 were missing, which were suspected dead (Liu et al., 2005). The fault ruptured a portion of megathrust fault that measures $\sim 1300-1500 \mathrm{~km}$, and this caused a magnitude 9.1-9.3 earthquake (Shearer and Bürgmann, 2010). The megathrust faults resemble the thrust faults found on land but are very large in extent. For example, the Sunda megathrust runs south from Bangladesh, curving around the western and southern flanks of Sumatra, Java, Bali and eastern Indonesia to northwestern Australia, which stretches to a distance of about 5,500 km (Sieh, 2007). There are examples of megathrusts offshore of the Philippines, Taiwan, Japan and southeastern China. Similarly, there are megathrusts on land and the biggest one traverses Pakistan through India and Nepal, covering 2,500 km along the southern side of the Himalayan mountain range (Sieh, 2007; Shah, 2013a).

The Moment Magnitude (Mw) 9.1-9.3 Sumatra-Andaman earthquake is possibly the first earthquake event in Asia that has dramatically changed the perception of earthquake faults and associated hazards under oceans. The devastation of life associated with the earthquake and tsunami possibly suggests that past memory of such large scale destructive earthquakes in Indian Ocean provides no precedent (Jankaew et al., 2008). The tsunami caused wide-scale devastation at shores that have not witnessed such a disaster in 200 years or more (Dominey-Howes et al., 207). This reflects that either the past earthquakes were not associated with a tsunami or had occurred in the distant past with no historical record (Shearer et al., 2010). However, recent paleoseismic studies in Indonesia have mapped the occurrence and extent of past earthquakes that were associated with tsunami and has deposited sand bodies soon after AD 1290-1400 and AD 780-990 (Monecke et al. 2008; Jankaew et al., 2008). This makes sense because megathrust faults are expected to host a range of earthquakes and it will be not be surprising to find more of such evidence in the future. The aftereffects had a great impact on global administrative and scientific community, and with it the rebirth of tsunami research took place, which is always a good thing. But, unfortunately, it often takes a devastating earthquake or a similar major disaster to awaken the global or local community to act. Hence the sad reality remains that administrative authorities usually need such events to take preventive measures (see below).

The 2014 earthquake mobilized Indonesian authorities to work on the science and mitigation planning. Now the nation is linked to a tsunami detection system in the Indian Ocean as are many other nations in the vicinity of Sunda megathrust. This is a great initiative to alert people in advance about an impeding tsunami disaster. The tsunami detectors existed only in the Pacific, and had such a system existed in the Indian Ocean prior to the 
devastating 2004 event approximately some 51,000 people, who lost their lives in Sri Lanka and India, would have been saved. A number of earthquake awareness programs have been conducted and many are in progress. In addition, a handful of evacuation shelters have been built in Banda Aceh and other vulnerable cities, although such a small number is unable to accommodate the growing population of Indonesia (Sieh, 2007), and could perhaps make situations out of control during an actual earthquake. This was put to test recently when On April 11, 2012 a magnitude 8.6 earthquake occurred in Banda Aceh. The earthquake alert system of Indonesia's National Tsunami Warning Center quickly issued a tsunami warning within five minutes of the first tremors. While the early warning system worked, unfortunately, the local response was too chaotic, and most of the city was in a mess. This could have happened due to the lack of proper emergency guidelines for the city evacuation program, as most of the people were stuck on roads. Although the earthquake event did not led to a tsunami, but the failure of proper evacuation exercise suggests that authorities failed a disaster preparedness test. And therefore, it is time to learn from this and get ready for a major disaster that is inevitable in the region (Sieh, 2007).

\subsection{Earthquake hazard on the Sumatran fault system, Indonesia}

The existence of $1900 \mathrm{~km}$ long Sumatran fault system, which is a major dextral strike-slip fault system in Indonesia and runs parallel to Sunda megathrust (Sieh and Natawidjaja, 2000), suggests that it accommodates trench parallel component of the regional oblique plate movement that causes active subduction of the oceanic crust of Australian Plate below the Sunda Plate (Fig. 1). Such large-scale strike-slip fault systems develop worldwide in tectonic regions where oblique compression or extension occurs, and the presence of such fault system could indicate their dominant role in slip partitioning during oblique interaction of two or more tectonic plates.

The historical earthquake events on the Sumatran fault system are not well constrained and possibly it has generated many earthquakes with moment magnitude (Mw) greater than 7 (Sieh and Natawidjaja, 2000). Recent report suggests that on an average, a major earthquake occurs along the fault system every 5 years (Natawidjaja, 2018). And unfortunately, studies on the tectonic, earthquake, and structural complexity of the Sumatran fault system have not gained as much attention as on the nearby Sunda megathrust. Interestingly, before the great 2004 Indian-Ocean tsunami the Sunda megathrust shared a similar fate of obscurity among researchers, and public at large. This means that we tend to wait for a major earthquake to wake us up and start exploring the science of such earthquake causing faults. Fortunately, this attitude seems to have changed to some degrees in recent years and now efforts are in progress to understand faults and why they are where they are.

\subsection{Sagaing fault (SF) and Main Himalayan/Frontal Thrust (MHT/MFT)}

The geographic, tectonic and geologic setting of Myanmar (Burma in past) is very interesting because it displays some of the key tectonic elements of regional tectonics in SE Asia (Fig. 1). Earthquake hypocenters suggest that presently Myanmar is dominantly undergoing strike slip faulting and it is broadly related to $\sim \mathrm{N}-\mathrm{S}$ and $\sim \mathrm{NE}-\mathrm{SW}$ trending faults (e.g. Sloan et al., 2017). These strike-slip faults suggest obliquity of plate movements in the region, which are related to the ongoing oblique collision of eastern margin of the Indian Plate with the Burma platelet (Fig. 1). The ongoing subduction along this region is 
controversial and so is the extent of the Sunda megathrust to north and below Burma (e.g. Sloan et al., 2017). It seems more reasonable to believe that Sunda megathrust terminates at the eastern Himalayan Syntaxes (e.g. Wang et al., 2014) because the seismological data mainly show strike-slip faulting (Sloan et al., 2017; Wang et al., 2014). Therefore, it may be convincing to say that present-day Myanmar is mainly releasing tectonic strain via strikeslip faulting. However, the existence of $\sim \mathrm{N}-\mathrm{S}$ trending folds and thrust belt in east suggests $\sim \mathrm{E}-\mathrm{W}$ compression but the absence of active thrusting could mean that the active subduction is either locked or slowly accumulation strain. The clear nature of active strike-slip faulting is manifested on the large scale dextral fault system known as Sagaing fault that extends for about $1400 \mathrm{~km}$ and passes through Myanmar and poses continuous earthquake risk in the region (Taylor and Yin 2009). It has hosted a number of destructive earthquake in the past and has the potential to host major earthquakes in the future (Wang et al., 2014).

To the north of Sagaing fault is the emergence of Main Himalayan/Frontal Thrust (MHT/MFT), which marks the surficial expression of the megathrust fault where an abrupt topographic high mark the end of Indo-Gangetic plains (Taylor and Yin, 2009) and the start of frontal mountain ranges (Fig. 1b). This fault system, which is younger than the other faults system north of it, remind us of the continuous push of the India tectonic plate against the Eurasia plate that has resulted in the formation of this megathrust fault since Eocene (Le Forte, 1975). Since the two continents are in collision therefore earthquakes are frequent, and most of them usually occur on the frontal fault system, with some on the interior faults (Shah, 2013; Shah and Malik 2017). Some of the prominent earthquakes that are associated with significant damage are: the 2005 Kashmir earthquake $(M w=7.6)$, the 1905 Kangra earthquake $(\mathrm{Mw}=7.7)$, the $2015 \mathrm{Nepal}$ earthquake $(\mathrm{Mw}=7.9)$, the 1934 Bihar-Nepal earthquake $(M w=8.1)$, the 1879 Shillong earthquake $(M w=8.1)$, and the 1950 Assam earthquake ( $\mathrm{Mw}=8.4$; e.g. Ambraseys and Douglas, 2004; Mugnier et al., 2013; Gupta, 2015).

The measurement of interseismic strain is therefore one of the most important aspects to understand the seismic hazard to millions of people who live in the closer vicinity of this deadly fault system (Taylor and Yin, 2009). The devastation nature of Mw 7.6 earthquake on 8 October 2005 in northern Pakistan and Kashmir region (Fig. 1) which caused more than 80,000 deaths (Pathier et al. 2006) is a continuous reminder that scientific progress is highly needed to understand the interiors faults as well. Since this earthquake occurred on one the interior fault system of NW Himalaya, it reactivated the Tanda and the Muzaffarabad fault systems (Fig. 1) (Shah and Malik, 2017), which were not listed as active faults on the available seismic risk maps of the region (Naseer et al., 2010).

\subsection{Progress in building of resilient infrastructure and communities to handle potential earthquake disasters}

Undoubtedly, a large portion of population in Pakistan, India, Nepal, Bangladesh, Myanmar, Thailand, Malaysia, and Indonesia lives on or nearby active fault systems (Fig. 4). Unregulated urbanization, coupled with many folds increase in populations, particularly in the last few decades have put these regions at greater earthquake risk.

First, the Indo-Gangetic plains in India abruptly rise at the foothills of Himalayas where Himalayan frontal fault system emerges at surface (Malik et al., 2010; 2014; 2015; Sapkota et al., 2013) at certain regions but mostly runs blind (Kumar et al., 2001). A series of devastating earthquake in the past are a reminder that earthquakes have greatly shaped the landscape and its history, and often some of the major or devastating earthquakes are 
recorded in the historical text (Ambraseys and Douglas, 2004). Surprisingly during the earlier periods of human settlements, including the latest British India, no standard seismic building codes were enforced or implemented. Past records show that during the later stages of British India seismic resistant building codes were planned after the devastating 1935 Quetta earthquake in Balochistan. Similarly, strengthening techniques are reported to have been implemented after the 1941 Andaman Islands earthquake (Jain, 2016).

It is important to note that Greater India achieved independence from British rule in 1947, but at the cost of regional instability that was marked by one of the most brutal partitions in the world (e.g. Talbot and Singh, 2009). The entire region was torn on religious lines with the creation of Hindu dominated India and Muslim dominated Pakistan (both East and West Pakistan at that time). What is more, the seeds of partition sprouted again with the emergence of East Pakistan (Banu and Sussex, 2001), again on blood-filled notions, into an independent nation, Bangladesh. During this time these newly created nations witnessed deadliest riots, bloodshed, and total devastation from national and international wars (Talbot and Singh, 2009). Therefore, any previous effort of planning or implementing of the earthquake resistant building codes, as was done in Quetta (read below), was delayed. This clearly suggests that political stability of a nation is paramount to its preparedness to face any kind of disaster, and thus India, Pakistan, and Bangladesh were unable to achieve objectives to safeguard its populations from disasters. All these countries are still struggling to get out of the ruins of partition to implement seismic code, and in India it again picked up in the late 1950s when India was fully independent. India started working towards the development of infrastructure for education and development but still lagged in planning of resistant seismic building codes.

Unfortunately, it takes a devastating earthquake to research, plan, and implement strategy to counter future potential disasters. This was apparent in most of SE Asia after the deadly event of 2004 (Sieh, 2007). In Pakistan, the huge loss of life and property that followed the 2005 Kashmir earthquake (see below) reminded authorities that there is a serious need to address this issue (Pathier et al. 2006). Likewise, in India the "Republican Day" earthquake of January 2001, that devastated Bhuj (Gujarat) with more than 19000 casualties (Bendick et al., 2001), did exactly this. After this earthquake both authorities and scientists kick started a comprehensive planning to understand the causes of earthquakes, and to plan and implement the seismic resistant building codes and earthquake education at large. Therefore, the National Information Centre of Earthquake Engineering was established, and with it a widespread 4-year National Programme on Earthquake Engineering Education that is implemented at Indian Institutes of Technology and the Indian Institute of Science, and it has developed a large scale education and training framework in India (Jain, 2016). However, a large portion of work remains to be achieved, particularly in rural areas where implementation of strict building codes is not practiced (Ambraseys and Bilham, 2011).

Second, Pakistan shares a similar political background as of India, rests on geological structures, and some of them are active and capable of producing deadly earthquakes (Quittmeyer and Jacob, 1979; Nakata, 1989; Shah and Malik, 2017). It was the devastating Quetta earthquake of May 30 th 1935 that caused a large scale damage in Quetta, and resulted in 60,000 casualties (Naseer et al., 2010). This perhaps forced the British authorities (who controlled it at that time) to enforce a strict building codes, Quetta Building Code, and it was 
subsequently adapted in 1937. The construction of unreinforced masonry buildings was forbidden. This standard practice is reported to have saved people and property during the 1941 earthquake (Naseer et al., 2010). After independent from British India in 1947, British India was torn into Pakistan and India on religious lines, resulting in one of the most brutal partitions of human history (Talbot and Singh, 2009). These scars were fresh when another massacre unfolded, and the East Pakistan independence struggle heated up with the formation of a new country called Bangladesh. This explains the delay in preparation and implementation of seismic resistant building codes in these regions, and thus after a period of relatively calm political atmosphere Pakistan developed 1986 Pakistan building code, which however had many problems, and did not reflect the ground realities, and even earthquake hazard zoning was greatly flawed. And it failed litmus test in 2005 when the Moment magnitude (Mw) 7.6 earthquake devastated Muzafferabad, and caused extensive damage and a loss of more than 80,000 people (Pathier et al. 2006). The country was violently shaken by the loss of people and started to rethink over the adaptation of strict building codes, and in 2007 Pakistan Building Code was adapted, which is mostly based on the 1997 Uniform Building Code. However, on ground the implementation measures will have to go a long way (Ambraseys and Bilham, 2011).

The third is in Nepal. Most of the dwellings in Nepal are located on the Himalayan megathrust fault, and therefore, highly prone to earthquake risks (Fig. 1). The country owns its existence to a number of fault system that traverse through it, and have shaped its geometry, structure, morphology, and geology over the geological past (Le Forte, 1975). Therefore, throughout its history it has been a victim of earthquake disasters (Bilham and Jackson, 1995). On 25 $5^{\text {th }}$ April 2015 the Mw 7.8 Gorkha-Nepal earthquake occurred on this fault system and caused extensive damage with more than 8,000 deaths (Avouac et al., 2015).

Historical text suggests that from 1768 to 2008, Shah and Rana dynasties ruled Nepal for about 250 years. While Nepal is the only country in South Asia that was not colonized by British, the internal political atmosphere has been largely unstable, particularly from the last two decades. In 1996 communist Maoist rebels started their armed struggle against the monarchs, and more than 13000 people lost their lives as a consequence of civil war till 2006 (Thapa and Sijapati, 2004; Achariya, 2009). Peace treaty was signed in 2006 between the government and Maoist insurgents, and in 2007 monarchy was officially abolished (Acharya, 2009). Since 2008 tension between the Nepalese Congress and Maoists for the political gains and influence has caused much instability within the country. This is possibly one of the major reasons for not following proper building codes to challenge seismic hazards.

Nepal has a recorded history of earthquake occurrences and related damage from at least 1255 AD. During 1833 an earthquake of magnitude 7.7 on Richter scale (MMI-X) destroyed more than 18000 buildings (Parajuli et al., 2000). In 1934 Nepal-Bihar earthquake an earthquake of magnitude 8.3 on Richter scale (MMI-X) caused massive destruction to life and infrastructure (Bilham et al., 2001). This does little to influence authorities too to devise a strong policy to address the problems related to earthquake hazards (Parajuli et al., 2000). Similarly, in 1988 Nepal faced another earthquake (Udaypur earthquake) of magnitude 6.4 on Richter scale and it killed more than 800 people and destroyed 66541 buildings (Dixi et al., 2013). This event jolted the Monarchs of Nepal and they requested the assistance from World Bank and the United Nations Development Programme (UNDP) to run a rehabilitation programme in the earthquake affected area. This quake forced the authorities to implement 
proper building codes in the country. And therefore, in 1992 the "Building Code Development Project" was launched. The idea was to improve the seismic safety aspects of the existing buildings and develop earthquake proof buildings in near future to diminish the impact of any earthquake disaster in near future (Chaulagain et al., 2015). In the recent past the Moment Magnitude (Mw) 7.8 earthquake that struck Nepal in April 2015 caused extensive damage to infrastructure, and killed more than 8000 people (Takai et al., 2016). This event again highlighted the immense need, and significance of developing, and implementation of proper and updated Building Code Project that was introduced in 1992.

The fourth country is Bangladesh. Most of Bangladesh is located on the Ganges Delta where three plates interact: the Indian Plate, the Eurasian Plate and the Burma Platelet (Fig. 1). This location is tectonically very critical because it demarcates the northern extent of Sunda megathrust, which $\sim$ trends $\sim$ NNW-SSE in this region and terminates at Shillong Plateau (Fig. 1). Here the $\sim \mathrm{E}-\mathrm{W}$ trending Himalayan frontal thrust faults have juxtaposed Indian Cratonic rocks against the Holocene to Recent Indo-Gangetic sediments (Figs. 1 and 2). Thus, this region is very prone to earthquake hazards (Stone, 2011) and needs a rigorous planning to deal with it. The Quetta code is possibly the first code and was developed and implemented during British era. After independence from British in 1947, Bangladesh was acquired by Pakistan under the partition planning but later Bangladesh opted out, and fought a bloody war to become an independent nation in 1971. The newly established nation with brutal occupation memories, poor economic condition, developing political stability, coupled with a variety of destructive natural disasters, had to struggle hard to emerge as a prosperous country. This struggle is ongoing and partly reflects the delay in implementation of solid strategy to build infrastructure, manpower, and scientific progress to tackle disasters. Once the post-colonial hangover is over, there are bright chances that the nation will flourish, and it has progressed quite a bit (Fig. 5). The Bangladesh National Building Code (BNBC) started in 1993 to work towards achieving of the seismic resilience of structures and society (Bari et al., 2013). The Bangladeshi authorities are working to improve and update BNBC 1993 and a draft copy of this has already been prepared (Bari et al., 2013) which is called BNBC 2010 (draft). The final report is not yet available.

The fifth is Myanmar. Burma (now Myanmar), a former British colony, achieved independence in 1948. The modern boarders of Myanmar are largely planned and demarcated during the British rule, because until 1937 British Burma was a province of British Indian empire (Taylor 2007). Unfortunately, a number of vicious ethnical and religious uprising and conflict cycles followed the independence, similar to what British India witnessed. Such conflicts are still very much there (Chan, 2005), continuously posing serious threats to not just Myanmar, but most of SE Asian regions. In such circumstance it is hard to imagine that a poor country will quickly develop or excel in developing a mitigation planning for earthquake hazards, which have always struck this country, and a few were very destructive (Wang et al., 2014). It is reported that before 1988 the requirement to have earthquake resistant structures was optional, and most of the major building projects were undertaken by government (MacRae et al., 2011). With increasing population, and a prolonged, post-colonial, relatively stable phase the private sector start flourishing, and between 1988 and 2002 taller structures (8 or more stories) had to follow seismic risk instructions in some parts of the country, like in Yangon (MacRae et al., 2011). After 1992 
that seismic evaluation of 3 story buildings started, which required examination from professional and licensed engineers. During the period the country had adapted British Standards (BS) and American Concrete Institute (ACI) codes (MacRae et al., 2011). Myanmar is in the process of developing national code, and hopefully the country takes utmost care in adapting updated seismic risk models for the entire country.

The sixth country is Indonesia. The Dutch colonization of Indonesia finally ended in 1949 when the people of Indonesia launched a four-year independence war to expel the Dutch control over the territory. Although Indonesia proclaimed independence in 1945 (Juwono, 2016), the Dutch rulers fought this declaration ruthlessly, resulting in major conflicts and bloodshed. This followed a continuous redrawing of SE Asian boarders, and therefore political stability was at stake. Thus, it took decades of painstaking hard work for Indonesia to finally come to the present stage where it has reached to some economic independence.

The population of Indonesia is expected to grow from 238.5 to 305.7 million between 2010 and 2015 (Indonesian Bureau of Statistics, 2014). Most of Indonesia sits on active faults, which pose serious earthquake and tsunami risks (Sieh, 2007). Therefore, residential buildings and other structures ought to be constructed in a very strict supervision of engineers, and geologists so that proper structures are built to save lives in future. This needs a proper planning and detailed earthquake hazard assessment in which exceedance levels of ground motion for different return periods and frequencies of wave motion are examined, and specified (Cummins, 2017). This has been done, and partially implemented, and therefore, buildings must abide by the strict building code requirements in most of Indonesia since at least 2002 (SNI-1726).

The building code (SNI-1726) is a revised version of an earlier code (SNI-03-1726). The codes are revised periodically, and when needed so that updated codes are implemented. The newly published report (Natawidjaja, 2018) shows that the seismic hazard map of the Sumatran Fault Zone has been revised. However, the task to fully equip this country with a resilient mechanism to counter earthquake and tsunami hazards is very difficult and demanding. This is mainly because of increasing population (Fig. 5) that demands more manpower to guide and help people in achieving of the goal.

Seventh, Malaysia, like many other countries in SE Asia, shares a similar story of British colonization. During British rule, Malaya nation was comprised of the Malay peninsula states of the Federated Malay States, the Unfederated Malay states plus the Straits Settlements of Penang, Singapore and Malacca. After World War II, the federated and un-federated Malay states along with states of Malacca and Penang joined and formed Malayan Union, and the Federation of Malaya was official formed in 1948. This newly formed Malaya nation finally gained independence from Britain in 1957, while Singapore separated from Malaysia in 1965 (Stivens, 2010). This clearly suggests that Malaysia is a newly formed nation, which had to put a great effort in stabilizing the newly formed country, and to become a vibrant economy. With this background it would be hard to imagine that Malaysia could have developed or realized the need to have a robust mechanism to counter natural disasters, including earthquakes. However, since its formation it has not witnessed a major earthquake(s), and that is possibly one of the major reasons for not working towards mapping and understanding of nature of active versus inactive faults throughout the country. Both west and east Malaysia are located away from the active plate boundaries (Fig. 1), and this has always been argued as the reason for no major seismicity in the region (e.g. Shah, 2015; Hall, 
2008). However, there is evidence of ongoing deformation (Sapin et al., 2011; Shah et al., 2018), which is usually revealed by the occurrence of earthquakes in the region, and mostly at the NW portions of the Island (Sapin et al., 2011; Shah, 2015; Wang et al., 2017,). When the medium magnitude earthquake struck Sabah on 5th June 2015, which is considered as the biggest recorded earthquake in the history of the region, it killed 18 people (Wang et al, 2017) and literally puzzled the local and scientific community (Shah, 2015; Wang et al, 2017; Shah et al., 2018). This event created panic and ripples in local, and international communities, and the Malaysian authorities have now mobilized its manpower to understand the cause of earthquakes in the region, and to recess the possibility of earthquake hazards in the country. Therefore, Malaysia is reported to follow Eurocode 8 (EC8) in designing buildings to resist earthquake shaking. In this regard they have developed and drafted Malaysia National Annex (NA to MS EN1998-1) document, which has been approved by the Technical Committee to undertake the task (Hee et al., 2015). The final information about this is not available as we compile this paper.

The scientific wisdom in understanding of the earthquake geology of South and Southeast Asia is slowly increasing but more work is needed to communicate this knowledge to people. And unfortunately most of the South and Southeast Asian countries had a turbulent past, and these nations are still struggling to come out of the colonial past, especially in terms of poverty, political stability, education, and the development of infrastructure. Therefore, it will be difficult to compare these nations with the developed nations e.g. Japan, United States or New Zealand. The continuous occurrence of earthquakes in Japan have made this nation to accept the fact that living with earthquake hazards is a reality, and therefore, the country has become one of the most resilient countries on the planet today (Paton at al, 2010). Yet, the Mw 9.0 earthquake that shattered Japan in 2011 caused extensive damage because of tsunami, and this resulted in loss of 20350 people (Elliott, 2002). Imagine the extent of devastation if such a large magnitude earthquake occurs in South or South East Asia (Fig. 6). Undoubtedly, Japan has developed infrastructure, science, technology, and more so a strong community culture (e.g. Elliott, 2012) to face the incoming challenges of disasters. This was possible because the country has a decent leadership, low corruption, high scientific literacy rates, and most importantly, a stable political structure. This is evident when we, for example, compare the economic condition of Argentina and Japan. Historians tell us that at the start of $20^{\text {th }}$ century Argentina was one of the wealthiest countries in the word, and in 1960 its income per capita was among the top 20 in the world, and definitely better, and higher than Japan (e.g. Alesina et al., 1996). However, this has changed dramatically in the last thirty years because of political instability and violence. The country has come closer to economic collapse. The role of political stability is again shown by the increased economic welfare of Japan, which in 1960 was much below than Iraq (look at Iraq now), Ireland, and Argentina and was not listed in the top twenty-five in the world (Alesina et al., 1996). With a good political stability, which has acted as a solid backbone, Japan has emerged, and acquired one of the fastest economic growth rates in the world (Alesina et al., 1996). 

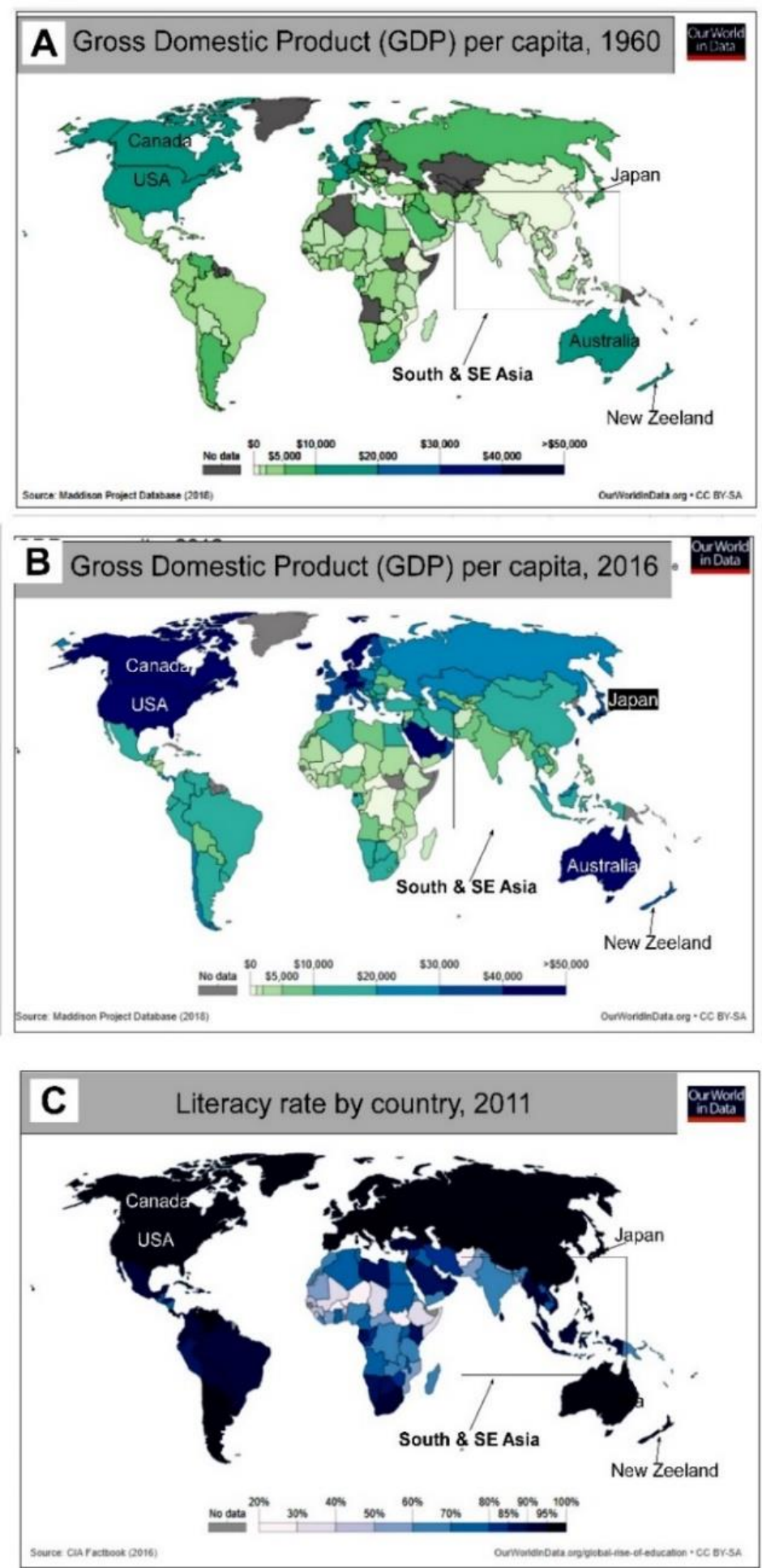

Fig. 4 (a) Shows the global distribution of Gross Domestic Product per capita, and this is significant for South and SE Asian countries, which were newly independent. The 2016 data. (b) shows significant improvement in GDP rates, and this is a good indicator for progress. (c) Impressive progress has been made in achievement of literacy rates, and this is very impressive for SE Asia.

Source: These figures are prepared from the data obtained on $26^{\text {th }}$ February, 2018 from Max Roser (2018). 



Fig. 5 (a) Shows the global distribution of population density. Date are from Robert Simmons, retrieved on $28^{\text {th }}$ February 2018. The latest regional probabilistic seismic hazard map (Chan et al., 2017) is overlain on the population density map (b) to show the number of people at earthquake risk in SE Asia where such a map is available. Jakarta stands out on the map with a huge population at risk. 

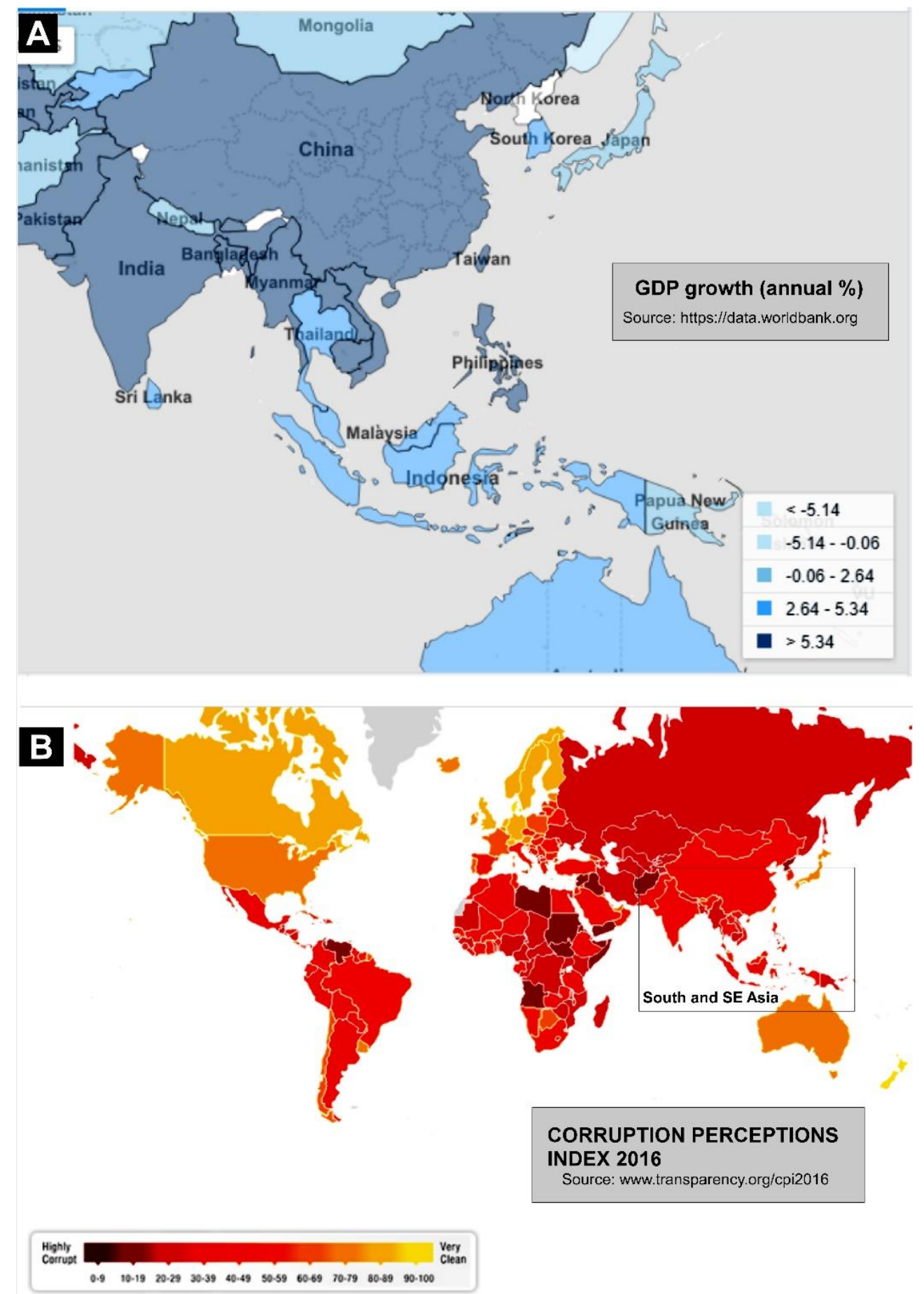

Fig. 6 (a) Annual GDP growth rates of South and South East Asian countries are shown against the (b) corruption perception index map, which suggest a great need to eradicate corruption to progress in leaps and bounds.

Source: These figures are prepared from the data obtained on $3^{\text {rd }}$ March 2018 from World bank, and Transparency International. 
The countries like India, Pakistan, and Bangladesh are actively engaged in improving of the earthquake science and related outreach activities. However, because of the increasing population, poverty, coupled with political problems these nations are struggling to make an impact on round. For example the urban population in the Indian Ganges Plain, which is located closer to the Himalayan frontal fault, has increased by a factor of ten since the 1905 Kangra earthquake (Bilham et al., 2001) that struck north-west Himalaya and killed 20,000 and destroyed 100,000 buildings (Ambraseys et al., 2000). The situation today is very disturbing because more than 50 million people are now at risk from great Himalayan earthquakes. Similarly, the capital cities of Bangladesh, Myanmar, Bhutan, India, Nepal, Pakistan, Indonesia, Malaysia, and several other cities that house a million inhabitants and more are vulnerable to damaging earthquakes in future (Fig. 5; Bilham et al., 2001).

Even with all of the past turbulence most of the South and Southeast Asia nations have progressed, which is evident from the post-independence values of gross domestic product (GPD) per capita (Fig. 5a and 5b). The other indicator of a good performance is a decent rise in literacy rates, and this is particularly true to SE Asian nations. This suggests that these nations have the potential to counter future disasters with greater efficiency. However, when we compare the corruption perception index (Transparency International, 2018) and annual GDP growth rates (in \%) the situation becomes difficult and suggests that most of these nations have to work really hard to eradicate corruption. This seems to align with earlier works (Ambraseys and Bilham, 2011; Bilahm et al., 2001) that corruption kills a society, and makes monsters out of disasters. However, here we strongly suggest that a nation with a stable political landscape will efficiently secure its people against any disaster. Therefore, if international, and national political atmosphere remains favorable for a nation there are more chances that such a nation will win, even with decent GDP growth rate, than a nation with high GDP growth rate but with political instability.

\section{Conclusions}

The scientific progress towards earthquake hazards in South and Southeast Asia is progressing, and a large number of researchers are actively working to understand the earthquake geology of this region. However, more scientific work is needed to fully comprehend the tectonics, and how to live with earthquakes. It is true that scientific progress is one of the major ingredients to fight earthquake hazards but a number of other important factors (discussed above) also play an important role, and must be considered. For example bulk of South and SE Asian regions have attained independence recently, and some have not celebrated 100 (some not even 50) years yet, and therefore it is anticipated that in the near future the political structures remain stable and corruption remains out of reach. We think these two ingredients are essential to win a war with disasters, and particularly earthquakes. And the fact that post-independence periods have remained turbulent, and traumatic, and some of the nations had to put a lot of effort on clearing of the aftermaths of independence, therefore, we hope in future these nations will progress further for the safety and security from earthquake disasters.

Furthermore, one of the important steps towards achieving the goal of becoming an earthquake resilient community is to work with the communities on ground and to engage in scientific awareness and preparedness campaigns. Such exercises often require an extensive network of various education-outreach activities, which include providing of quality earthquake education resources and scientific training to local communities, which 
will be used to build an earthquake resilient community culture. And therefore, in South and Southeast Asia the earthquake education and outreach engagement programme has to reach each and every household, and that is how one can possibly win the ongoing battle with the potential earthquake hazards in the region.

\section{Acknowledgements}

We are thankful to reviewers for their comments and suggestions, which greatly helped and improved our contribution. The financial support from the National Geographic Society, US, is highly appreciated. The authors are also very thankful to Dr. Chan (Earth Observatory of Singapore) for providing the latest regional probabilistic seismic hazard map of SE Asia.

\section{References}

Acharya, A. (2009). The Maoist insurgency and the political economy of violence. The Maoist Insurgency in Nepal: Revolution in the Twenty-first Century, 20, 263.

Alesina, A., Özler, S., Roubini, N., \& Swagel, P. (1996). Political instability and economic growth. Journal of Economic growth, 1(2), 189-211.

Ambraseys, N., \& Bilham, R. (2011). Corruption kills. Nature, 469(7329), 153.

Ambraseys, N., \& Bilham, R. (2000). A note on the Kangra M s= 7.8 earthquake of 4 April 1905. Current Science, 79(1), 45-50.

Avouac, J. P., Meng, L., Wei, S., Wang, T., \& Ampuero, J. P. (2015). Lower edge of locked Main Himalayan Thrust unzipped by the 2015 Gorkha earthquake. Nature Geoscience, 8(9), 708.

Bilham, R., Gaur, V. K., \& Molnar, P. (2001). Himalayan seismic hazard. Science, 293(5534), $1442-1444$.

Bilham, R., Bodin, P., \& Jackson, M. (1995). Entertaining a great earthquake in western Nepal: historic inactivity and geodetic tests for the present state of strain. Journal of Nepal Geological Society, 11(1), 73-78.

Bari, M. S., \& Das, T. (2013). A Comparative Study on Seismic Analysis of Bangladesh National Building Code (BNBC) with Other Building Codes. Journal of The Institution of Engineers (India): Series A, 94(3), 131-137.

Banu, R., \& Sussex, R. (2001). English in Bangladesh after independence: Dynamics of policy and practice. 122-147.

Bendick, R., Bilham, R., Fielding, E., Gaur, V. K., Hough, S. E., Kier, G., ... \& Mukul, M. (2001). The 26 January 2001 “Republic Day” earthquake, India. Seismological Research Letters, 72(3), 328-335.

Chaulagain, H., Rodrigues, H., Silva, V., Spacone, E., \& Varum, H. (2015). Seismic risk assessment and hazard mapping in Nepal. Natural Hazards, 78(1), 583-602.

Chan, A. (2005). The Development of a Muslim Enclave in Arakan (Rakhine) State of Burma (Myanmar). SOAS Bulletin of Burma Research, 3(2), 396-420.

Chung-Hn Chan., Yu Wang., Xuhua Shi., Teraphan Ornthammarath., Pennung Warnitchai., Suwith Kosuwan., Myo Thant., Phuong Hong Nguyen., Le Minh Nguyen., Renato U Solidum Jr., Masyhur Irsyam., Sri Hidayati, \& Kerry Sieh (2017). Toward uniform probabilistic seismic hazard assessments for Southeast Asia. American

Crowley, K., \& Elliott, J. R. (2012). Earthquake disasters and resilience in the global North: lessons from New Zealand and Japan. The Geographical Journal, 178(3), 208-215. 
Cummins, P. R. (2017). Geohazards in Indonesia: Earth science for disaster risk reductionintroduction. Geological Society, London, Special Publications, 441(1), 1-7. Geophysical Union-245.

DesRoches, R., Comerio, M., Eberhard, M., Mooney, W., \& Rix, G.J. (2011). Overview of the 2010 Haiti earthquake. Earthquake Spectra, 27(S1), S1-S21.

Dixit, A. M., Yatabe, R., Dahal, R. K., \& Bhandary, N. P. (2013). Initiatives for earthquake disaster risk management in the Kathmandu Valley. Natural hazards, 69(1), 631-654.

Dominey-Howes, D., Cummins, P., \& Burbidge, D. (2007). Historic records of teletsunami in the Indian Ocean and insights from numerical modelling. Natural Hazards, 42(1), 117.

Forand, D., Evans, J. P., Janecke, S. U., \& Jacobs, J. (2018). Insights into fault processes and the geometry of the San Andreas fault system: Analysis of core from the deep drill hole at Cajon Pass, California. GSA Bulletin, 130(1-2), 64-92.

Genrich, J. F., Bock, Y., McCaffrey, R., Prawirodirdjo, L., Stevens, C. W., Puntodewo, S. S. O., ... \& Wdowinski, S. (2000). Distribution of slip at the northern Sumatran fault system. Journal of Geophysical Research: Solid Earth, 105(B12), 28327-28341.

Hall, R., van Hattum, M. W., \& Spakman, W. (2008). Impact of India-Asia collision on SE Asia: the record in Borneo. Tectonophysics, 451(1-4), 366-389.

Hee, M.C., Lam, N.T.K., Tsang, H.H. and Looi, D.T.W. 2015. Draft National Annex to Eurocode 8 for Malaysia and cost implication for residential buildings with thin size elements. Proceedings of the Tenth Pacific Conference on Earthquake Engineering Building an Earthquake-Resilient Pacific, 6-8 November 2015, Sydney, Australia. Australian Earthquake Engineering Society.

Hough, S. E. (2010). Predicting the Unpredictable: The Tumultuous Science of Earthquake Prediction. 272 pp.

Jain, S.K., 2016. Earthquake safety in India: achievements, challenges and opportunities. Bulletin of Earthquake Engineering, 14(5), pp.1337-1436.

Jankaew, K., Atwater, B. F., Sawai, Y., Choowong, M., Charoentitirat, T., Martin, M. E., \& Prendergast, A. (2008). Medieval forewarning of the 2004 Indian Ocean tsunami in Thailand. Nature, 455(7217), 1228.

Juwono, V. (2016). Berantas Korupsi: a political history of governance reform and anticorruption initiatives in Indonesia 1945-2014 (Doctoral dissertation, The London School of Economics and Political Science (LSE).

Kumar, S., Wesnousky, S. G., Rockwell, T. K., Ragona, D., Thakur, V. C., \& Seitz, G. G. (2001). Earthquake recurrence and rupture dynamics of Himalayan Frontal Thrust, India. Science, 294(5550), 2328-2331.

Le Fort, P. (1975). Himalayas: the collided range. Present knowledge of the continental arc. American Journal of Science, 275(1), 1-44.

Liu, P. L. F., Lynett, P., Fernando, H., Jaffe, B. E., Fritz, H., Higman, B., \& Synolakis, C. (2005). Observations by the international tsunami survey team in Sri Lanka. Science, 308(5728), 1595-1595.

MacRae, G. A., Myint, U. T., \& Jain, S. K. (2011). Steps in Earthquake Proofing a Country-A Case Study of Myanmar. Bulletin of the New Zealand Society for Earthquake Engineering, 44(2), 87.

Malik, J. N., Sahoo, A. K., Shah, A. A., Shinde, D. P., Juyal, N., \& Singhvi, A. K. (2010). Paleoseismic evidence from trench investigation along Hajipur fault, Himalayan 
Frontal Thrust, NW Himalaya: implications of the faulting pattern on landscape evolution and seismic hazard. Journal of structural geology, 32(3), 350-361.

Malik, J. N., Sahoo, S., Satuluri, S., \& Okumura, K. (2015). Active fault and paleoseismic studies in Kangra valley: Evidence of surface rupture of a great Himalayan 1905 Kangra earthquake (M w 7.8), Northwest Himalaya, India. Bulletin of the Seismological Society of America, 105(5), 2325-2342.

Malik, J. N., Shah, A. A., Naik, S. P., Sahoo, S., Okumura, K., \& Patra, N. R. (2014). Active fault study along foothill zone of Kumaun Sub-Himalaya: influence on landscape shaping and drainage evolution. Current Science, 229-236.

Malik, J. N., Sahoo, A. K., Shah, A. A., Rawat, A., \& Chaturvedi, A. (2007). Farthest Recorded Liquefaction Around Jammu Caused by 8 October, 2005 Muzaffarabad Earthquake of Mw= 7.6. JOURNAL-GEOLOGICAL SOCIETY OF INDIA, 69(1), 39.

Max Roser (2018) - "Economic Growth". Published online at OurWorldInData.org. Retrieved on 26 ${ }^{\text {th }}$ February from: 'https://ourworldindata.org/economic-growth' [Online Resource]

Max Roser and Esteban Ortiz-Ospina (2018) - "Literacy". Published online at OurWorldInData.org. Retrieved on 26 ${ }^{\text {th }}$ February from: https://ourworldindata.org/literacy' [Online Resource]

Natawidjaja, D. H. (2018). Updating active fault maps and sliprates along the Sumatran Fault Zone, Indonesia. In IOP Conference Series: Earth and Environmental Science (Vol. 118, No. 1, p. 012001). IOP Publishing.

Nakata, T. (1989). Active faults of the Himalaya of India and Nepal. Geological Society of America Special Paper, 232, 243-264.

Naseer, A., Khan, A. N., Hussain, Z., \& Ali, Q. (2010). Observed seismic behavior of buildings in northern Pakistan during the 2005 Kashmir earthquake. Earthquake Spectra, 26(2), 425-449.

NOAA Satellite and Information Service, National Environmental Satellite, Data, and Information Service. (2002) Retrieved on 26th February 2018, from https://maps.ngdc.noaa.gov/viewers/hazards/?layers=2\&extent=-180,70,180,-70

Parajuli, Y. K., Bothara, J. K., Dixit, A. M., Pradhan, J. P., \& Sharpe, R. D. (2000, January). Nepal Building Code-Need, Development Philosophy and Means of Implementation. In 12th World Conference on Earthquake Engineering, Auckland, New Zealand, January.

Pathier, E., Fielding, E. J., Wright, T. J., Walker, R., Parsons, B. E., \& Hensley, S. (2006). Displacement field and slip distribution of the 2005 Kashmir earthquake from SAR imagery. Geophysical Research Letters, 33(20).

Paton, D., Bajek, R., Okada, N., \& McIvor, D. (2010). Predicting community earthquake preparedness: a cross-cultural comparison of Japan and New Zealand. Natural Hazards, 54(3), 765-781.

Philibosian, B., Sieh, K., Avouac, J. P., Natawidjaja, D. H., Chiang, H. W., Wu, C. C., ... \& Lu, Y. (2017). Earthquake supercycles on the Mentawai segment of the Sunda megathrust in the seventeenth century and earlier. Journal of Geophysical Research: Solid Earth, 122(1), 642-676.

Quittmeyer, R. C., \& Jacob, K. H. (1979). Historical and modern seismicity of Pakistan, Afghanistan, northwestern India, and southeastern Iran. Bulletin of the Seismological Society of America, 69(3), 773-823. 
Robert Simmon, NASA's Earth Observatory, based on data provided by the Socioeconomic Data and Applications Center (SEDAC), Columbia University. Retrieved on $28^{\text {th }}$ February 2018, from https://neo.sci.gsfc.nasa.gov/view.php?datasetId=SEDAC_POP

Sapkota, S. N., Bollinger, L., Klinger, Y., Tapponnier, P., Gaudemer, Y., \& Tiwari, D. (2013). Primary surface ruptures of the great Himalayan earthquakes in 1934 and 1255. Nature Geoscience, 6(1), 71.

Sapin, F., Pubellier, M., Lahfid, A., Janots, D., Aubourg, C., \& Ringenbach, J. C. (2011). Onshore record of the subduction of a crustal salient: example of the NW Borneo Wedge. Terra Nova, 23(4), 232-240.

Shah, A. A., Zhafri, M. N., Delson, J., \& Navakanesh, B. (2018). Major Strike-Slip Faults Identified Using Satellite Data in Central Borneo, SE Asia. Geosciences, 8, 156.

Shah, A. A. (2013). Earthquake geology of Kashmir Basin and its implications for future large earthquakes. International Journal of Earth Sciences, 102(7), 1957-1966.

Shah, A.A. (2015). Understanding the recent Sabah Earthquake, and other seismogenic sources in North West Borneo. Scientific Malaysia, 11, 7-10.

Shah, A. A. (2013a). Megathrust earthquakes and the associated volcanic subsidence. Current Science, 105(5), 567-567.

Shah, A. A. (2014). Predicting the Unpredictable: The Tumultuous Science of Earthquake Prediction. Geosciences Journal, 18, 373-374.

Shearer, P., \& Bürgmann, R. (2010). Lessons learned from the 2004 Sumatra-Andaman megathrust rupture. Annual Review of Earth and Planetary Sciences, 38.

Sieh, K., \& Natawidjaja, D. (2000). Neotectonics of the Sumatran fault, Indonesia. Journal of Geophysical Research: Solid Earth, 105(B12), 28295-28326.

Sieh, K. (2007). The Sunda megathrust-past, present and future. Journal of Earthquake and Tsunami, 1(01), 1-19.

Sloan, R. A., Elliott, J. R., Searle, M. P., \& Morley, C. K. (2017). Active tectonics of Myanmar and the Andaman Sea. Geological Society, London, Memoirs, 48(1), 19-52.

Stone, R. (2011). A Bengali recipe for disaster. Science, 332(6035), 1256-1258.

Stivens, M. (2010, July). Religion, nation and mother-love: The Malay Peninsula past and present. In Women's Studies International Forum (Vol. 33, No. 4, pp. 390-401). Pergamon.

Takai N, Shigefuji M., Rajaure S., Bijukchhen S., Ichiyanagi M., Megh Raj Dhital MR, Sasatani $\mathrm{T}$ (2016) Strong ground motion in the Kathmandu Valley during the 2015 Gorkha, Nepal, earthquake Earth, Planets and Space, 68:10.

Talbot, I., \& Singh, G. (2009). The partition of India. Cambridge: Cambridge University Press

Taylor, M., \& Yin, A. (2009). Active structures of the Himalayan-Tibetan orogen and their relationships to earthquake distribution, contemporary strain field, and Cenozoic volcanism. Geosphere, 5(3), 199-214.

Taylor, R. H. (2007). British Policy towards Myanmar and the Creation of the "Burma Problem,". Myanmar: State, Society and Ethnicity, 70-95.

Thapa, D., \& Sijapati, B. (2004). A kingdom under siege: Nepal's Maoist insurgency, 1996 to 2003. Zed books.

Transparency International. (2018). Retrieved at $3^{\text {rd }}$ March 2018, from the website: https://www.transparency.org/news/feature/corruption_perceptions_index_2016 
Wang, Y., Sieh, K., Tun, S. T., Lai, K. Y., \& Myint, T. (2014). Active tectonics and earthquake potential of the Myanmar region. Journal of Geophysical Research: Solid Earth, 119(4), 3767-3822.

Wang, Y., Wei, S., Wang, X., Lindsey, E. O., Tongkul, F., Tapponnier, P., \& Sieh, K. (2017). The $2015 \mathrm{M} \mathrm{w} 6.0 \mathrm{Mt}$. Kinabalu earthquake: an infrequent fault rupture within the Crocker fault system of East Malaysia. Geoscience Letters, 4(1), 6.

World Bank. (2018). GDP growth (annual \%). Retrieved on 3 $3^{\text {rd }}$ March 2018 from https://data.worldbank.org/indicator/NY.GDP.MKTP.KD.ZG?type=shaded\&view=m ap\&year $=2016$ 